Психология. Журнал Высшей школы экономики.

2017. T. 14. № 2. C. 320-337. DOI: 10.17323/1813-8918-2017-2-320-337

\title{
СТАРОСТЬ КАК ПСИХОЛОГИЧЕСКИЙ И КУЛЬТУРНЫЙ ФЕНОМЕН
}

\author{
В.М. РОЗИН \\ ${ }^{2}$ Институт философии РАН, 109240, Россия, Москва, ул. Гониарная, д. 12, стр. 1
}

\begin{abstract}
Резюме
В статье старость рассматривается в рамках авторской концепции «культур жизни человека». Он предлагает различать «культуру детства», «культуру отрочества и юности», несколько «культур взрослого человека». Каждая культура жизни человека характеризуется особенностями жизнедеятельности и ви́дения (сознания), а также характером социализации. Приводится краткая характеристика каждой культуры жизни. Затем разбираются проблемы старости (расставание с привычным образом жизни, болезни, потеря смысла жизни и др.), а также традиционные способы, с помощью которых пожилые люди пытаются бороться с этими проблемами. Автор высказывает гипотезу, что сущность культуры старости - это выстраивание конщепции старости и ее реализация. В свою очередь, последняя предполагает, с одной стороны, изменение реальности и нахождение смысла своей жизни, с другой - возобновление жизни в новых условиях. На примере понимания здоровья человека и места, которое оно должно занимать в старости, обсуждаются условия реализации этой гипотезы. Здоровье отдельного человека, утверждает автор, сегодня лучше понимать не как отсутствие болезней или иллюзорное благополучие, а, прежде всего, как работу человека и качество, характер жизни, складывающиеся под влиянием подобной работы. Главные ее составляющие такие. Построение личной конщепщии здоровья (а на последнем этапе жизни - концепции старости). Включение в нее социальных требований к здоровью. Одновременно нужно развивать критическое отношение к услугам, которые предлагает государство или медицинский бизнес, корректировать их на основе своей личной концепции здоровья. Минимизация болезней с использованием как личных возможностей (здоровый образ жизни, работа с собственными ценностями и пр.), так и всех средств, предоставляемых обществом. Формирование установок на возобновление жизни и здоровья, что предполагает смену форм поведения и отношения к своему здоровью по мере старения. Умение работать и справляться со своими проблемами и стрессами. Подчинение всей указанной работы общему сценарию правильной жизни. Завершается статья обсуждением трех условий воспроизводства старости как культуры. Первый: эту культуру поддерживает общество, создавая для старческой жизни специальные условия и институты. Второй: сама биологическая природа работает на воспроизводство старости - люди стареют, болеют, идут к своему концу. Третий момент: совместная работа человека и культуры - человек создает индивидуальные концепции старости и реализует их, культура производит различные семиотики старости, которыми пользуются люди.
\end{abstract}

Ключевые слова: старость, возраст, концепция, смысл жизни, кризис, культуры жизни, болезни, страх, здоровье, смерть. 


\section{Три «культуры жизни человека»}

Единым человек является только в биологическом плане; как культурное и, возможно, духовное существо человек - не един. Существуют несколько «культур жизни человека» (мы предлагаем ввести такое понятие, как «культура жизни»): «культура детства», «культура отрочества и юности», несколько «культур взрослого человека». Каждая культура жизни человека характеризуется особенностями жизнедеятельности и ви́дения (сознания), а также характером социализации; в первых двух культурах важное место занимает образование.

Детство - это не только самостоятельная культура жизни, но и начало трудного перехода от одной жизни к другой (от «прамы» к личности; «прамы» - термин Л.С. Выготского, призванный подчеркнуть единство ребенка со своими родителями). В детстве два основных способа освоения мира: игра и становление первых сочиально значимых практик (умения есть, пить, говорить, одеваться, общаться со взрослыми, помогать им и т.п.). В Я ребенка имплицитно входят и его родители, которые могут быть рассмотрены как его «социальное тело». В чем культурный смысл детской игры? Это доступный ребенку способ освоения взрослого мира и первая репетиция свободы личности. Родители для своих детей являются настоящей $\mathrm{cno}^{-}$ собностью («социальным телом»): как только дети сталкиваются с проблемами, которые не могут решить, то тут же прибегают к помощи родителей. Мы со своими детьми - одно целое. Я не только отец для своего ребенка и субъект, с которым он общается, но и его органическая способность, позволяющая решать недетские задачи.

Смысл кризиса детства, о котором сегодня много говорят, - это, прежде всего, кризис нашей взрослой жизни. Современный человек создал жизнь, которая разрушает и его самого, и детей (соблазн желаний, соблазн техникой). Родители не живут вместе со своими детьми, передают их на воспитание другим. Сегодня чуть ли не главный воспитатель - среда, гедонистически ориентированная культура. Мы, взрослые, сами не знаем, как жить, поэтому детство - это «переход в переходы», в неопределенность.

Можно различить две разные зоны детства. В первой («безопасной») мы ведем ребенка и являемся его способностью. Во второй («опасной») родители учатся жить вместе со своими детьми. Выясняют для себя и детей, что можно, а что нельзя. Ответственные родители вынуждены кардинально пересматривать свою жизнь. Их направляют любовь к детям, разум, осмысление последствий наших поступков и поступков детей.

Отрочество и юность - не менее самостоятельная культура жизни. Ее центральный процесс - становление лииности (не развитие личности, а только постепенное ее складывание через пробы и ошибки). Подростковая культура начинает формироваться, когда родители (общество) посылают ребенка в школу, где от него требуют действовать самостоятельно. В значительной степени и школа, и родители блокируют теперь для отрока возможность решать свои проблемы в сфере игры и фантазии (сказки). Напротив, объем обучения 
постоянно возрастает, а требование дейст вовать рационально становится основным. Существенно изменяются и социальные отношения: вместо родительской опеки и поддержки складываются двусторонние властные (c педагогами и значимыми взрослыми) и равноправные (с друзьями) отношения.

Под давлением взрослых и школы распадается прамы, отрок начинает переходить к самостоятельному поведению, уиится управлять сам собой (планирует свои занятия, позиционируется по отношению к другим, центрирует мир на своем Я, разделяет внутреннее и внешнее и претерпевает прочие метаморфозы, достаточно хорошо описанные в художественной и психологической литературе). Отрочество неотделимо от школы и образования, в связи с чем на первый план выдвигается не игра, а рациональные типы поведения (учеба, рассуждения, первые анализы последствий своих поступков и пр.).

Взрослая культура (фактически две культуры: зрелости и старости, включающей также и пожилой возраст) - это время развития и завериения ставшей личности.

Итак, развитие человека - процесс дискретный. Подобно превращению гусеницы в куколку и последней в бабочку, человек в своем развитии обновляет несколько раз - один человек в детстве, другой (отрок и юноша) - в юности, третий - во взрослом существовании (причем тоже неоднократно).

\section{Проблемы старости}

Понятно, что по отношении к старости особенно трудно (если вообще возможно) описать развитие единой психики человека. В книге «Практическая психология старости» Марина Ермолаева пишет: «О старости много написано, но мало известно. Осталась нераскрытой величайшая тайна старости, которая заключается в том, что хронологические ровесники этого возраста могут относиться к различным психологическим возрастам: один пожилой человек переживает любовь - он вернулся в период юности; другой продолжает свою творческую профессиональную деятельность - он пребывает в зрелом возрасте; третий посвятил свою жизнь заботам о собственном угасающем здоровье (его удел - разговоры о докторах и лекарствах) - это действительно старость. Анализ литературы о психологии старости и старения, анализ биографий и автобиографий творческих людей, доживших до преклонных лет, показал, что старость как психологический возраст может и не наступить в жизни человека» (Ермолаева, 2002, с. 14).

Возникает естественный вопрос: если все так индивидуально и уникально, можно ли в таком случае чтото сказать о старости по сушеству или в плане закономерности? Ермолаева отмечает, что проблема выделения границ старости является очень сложной. По мнению членов Всемирной организации здравоохранения, более правильным представляется термин «стареющие», указывающий на процесс, а не на определенную и всегда произвольно устанавливаемую возрастную границу (Там же, с. 1).

Думаю, все же понять, что такое старость, можно, для этого, правда, 
нужно последовательно реализовать культурологический и гуманитарный подходы. Культуролог с подобной установкой, с одной стороны, старается в гуманитарном ключе понять феномен старости, с другой охарактеризовать его как идеальный объект (т.е. приписать старости контролируемые характеристики, позволяющие ее мыслить непротиворечиво и решить проблемы, которые волнуют исследователя). Здесь опять можно согласиться с Ермолаевой. «Этот возраст, - пишет она, - отличает особое предназначение, специфическая роль в системе жизненного цикла человека: именно старость очерчивает общую перспективу развития личности, обеспечивает связь времен и поколений. Только с позиции старости можно глубоко понять и объяснить жизнь как целое, ее сущность и смысл, ее обязательства перед предшествующими и последующими поколениями» (Там же).

Эта постановка вопроса не столько психологическая, сколько культурологическая и научная, но также ценностная, гуманитарная. Дело в том, что в реальной жизни есть много чего: старость такая и такая, и удовлетворительная (иногда даже счастливая) и несчастливая, но вот культуролог-гуманитарий должен уяснить и схематизировать «желательную старость». Именно в этом ключе можно понять последнюю строчку книги Ермолаевой: «Если бы жизнь завершалась старостью-катастрофой, старостью-деградацией, то она не имела бы смысла. Жизнь может и должна завершиться старостью-гармонией, старостью-мудростью, и для этого стоит жить» (Там же, с. 15).
Это, так сказать, в идеале, а опыт говорит, что «старость не радость»; кроме того, по отношению к последней культуре жизни человека встает много вопросов. Например, чем заполнить жизнь, чтобы она не теряла смысл, в другой версии - это проблема нахождения в этом возрасте смысла жизни. «Общество, - пишет священник Роман Бацман, - может освободить пожилого человека от его гражданских обязанностей, но оно не может освободить человека от обязанностей по отношению $к$ самому себе. Речь идет о самой главной обязанности человека - решении вопроса о смысле жизни и осуществлении его на практике. Важно не только понять свое предназначение, но еше исполнить его. Такая задача стоит, безусловно, перед всеми людьми, а не только перед пожилыми. Просто с течением времени нарастает острота вопроса о смысле жизни, так как времени и сил, отведенных для его решения и осуществления, с течением жизни остается все меньше» (Бацман, 2003, с. 53). М. Бахтин утверждал, что только смерть (в данном случае ее приближение) создает место для «точки вненаходимости», позволяющей завершить жизнь человека и впервые понять ее смысл. Другое дело, что в течение жизни некоторые люди, осмысляя свою жизнь, пытаются понять ее смысл и далее реализовать его. Подобное понимание-конструирование жизни личностью необходимый момент ее осуществления в европейской культуре. Одно из условий нахождения смысла жизни состоит в том, чтобы нащупать и выстроить правильный образ жизни. Вопрос, как это сделать. 
Вторая проблема - как преодолеть страх перед смертью? Избежать если не старости, то смерти люди мечтали с древнейших времен. О желании бессмертия, например, замечательно пишут поэты и «ученые» народа Нагуа, населявшие в древности большую Мексиканскую долину:

(Если) за один день мы уйдем

И за одну ночь спустимся в область тайны, И здесь мы только, чтобы узнать себя,

А на земле мы лишь мимоходом.

Мирно и радостно проведем жизнь:

Приходите и наслаждайтесь,

Пусть не приходят те, кто живет в злобе:

Земля очень широка!

Вот бы всегда жить,

Вот бы никогда не умереть!

(Леон-Портилья, 1961, с. 159)

Вряд ли найдется много людей, которые стали бы утверждать, что они бессмертны. Тем не менее большинство из нас живут, как будто мы бессмертны. Верующие прямо считают, что поскольку душа бессмертна и Бог существует, то рано или поздно они воскреснут, подобно тому, как воскрес древнеегипетский бог Озирис или Христос. Но не надо думать, что верующие не боятся смерти. «Для христианина, - пишет Бацман, - смерть великое таинство. Она - рождение человека из земной, временной жизни в вечность. В то же время - "что для человека всего ужаснее? - пишет святой праведный Иоанн Кронштадтский. - Смерть? Да, смерть. Всякий из нас не может без ужаса представить, как ему придется умирать и последний вздох испускать”. Истинно христианское отношение к смерти заключает в себе элемент страха, неуверенности, именно тех эмоций, которые хочет упразднить наша современная безбожная цивилизация. Однако в христианском отношении к смерти нет ничего от низкого страха, который могут испытывать умирающие без надежды на вечную жизнь, и христианин с умиротворенной совестью приближается к смерти, по Божией милости, спокойно» (Бацман, 2003, c. $81-82)$.

Неверующие стараются не думать о смерти и главное - жить. Вопрос, правда, как жить в старости при условии, что ты уже вышел на пенсию, болеешь и чувствуешь себя одиноким, а впереди ничего нет? Кстати, это и есть третья проблема старости: многие из нас болеют и одиноки, не видят перспективы в будущем, и, спрашивается тогда, как жить?

Конечно, не все, достигая преклонного возраста, не работают, болеют и одиноки. Многие стараются работать до конца, именно как бессмертные существа. Многие тратят все свои силы, чтобы быть здоровыми и чувствовать себя хорошо, но, как известно, еще никому не удалось избежать смерти. Многие не одиноки, поскольку работают и имеют поддержку в семье или со стороны друзей.

Если все же, как большинство людей, достигший пожилого возраста вышел на пенсию и оказался перед вопросом, как жить, он часто не то чтобы старается обмануть жизнь, а выстраивает ее, как может, одновременно в душе чувствуя, что эта жизнь как $б$ не совсем настоящая. Один способ, пожалуй, из лучших (исключая веру) - найти себя в творчестве. Начать писать мемуары, картины, сочинять музыку и пр. Как 
бъ в том, что впереди маячит смерть, криво усмехающаяся над твоими усилиями. Другой способ, особенно распространенный в нашей цивилизации, - развлечения. Пожилые люди не отрываются от телевизора, ходят на выставки и концерты, если позволяет здоровье, путешествуют, осваивают курорты и т.д. и т.п. Как бъ состоит здесь в конечности всех этих занятий и неотступном вопросе: а в чем смысл всего этого, зачем это, ведь не просто ради удовольствия и заполнения (убиения) времени жизни? Если же смысл не находится, то развлечения во многом теряют свою привлекательность, превращаясь в пустое занятие, в антижизнь. Еще один способ, тоже неплохой,начать помогать бездомным собакам и кошкам, а также всем, кто готов принять твою помощь. Как бы в данном случае в том, что человек не решает своих собственных проблем, оправдывая это занятостью и тем, что ведь он помогает. В каком-то смысле оправдание своей жизни (как много я сделал, взял от жизни, любил, наслаждался и пр.) - один из способов утешения и осмысления прошедшей жизни. Но опять как бы, ведь даже прекрасно прожитая жизнь перед лицом вечности и смерти перестает казаться прекрасной.

Есть еще один способ - просто жить, не размышляя, зачем и почему. «Среди отечественных ученых наиболее полно Н.Ф. Шахматов описал переживания стариков, связанные со смертью. На основании обзора многочисленных экспериментальных исследований он показал, что в основной своей части пожилые люди не боятся и не избегают разговоров о собственной смерти. Беседа с пожи- лым человеком на эту тему не носит для него травмирующего характера (конечно, при условии соблюдения такта и осторожности). Пожилые люди внешне не проявляли интереса к вопросам смерти. Обычными их ответами на вопросы соответствующего рода были: "Стараюсь не думать о смерти, какой в этом прок”, "Зачем думать о ней, какой в этом прок”, “Если буду чувствовать себя, как чувствую физически сейчас, готов жить сколько угодно”, “Боюсь не смерти, а физических страданий, которые могут ей сопутствовать". В высказываниях, отражающих отношение людей к смерти, можно увидеть личное решение основного вопроса, определяющего их жизненную позицию, - «Живи, пока живется». «Несмотря на, казалось бы, наивный философский характер заключения, его значение не может быть преуменьшено, так как именно в этом можно увидеть итог жизненного личного Опыта» (Ермолаева, 2002 , с. 6). Но заметим, что говорит собеседник: «Стараюсь не думать о смерти»; не означает ли это, что он о ней очень даже думает и, возможно, боится смерти, но, как выбраться из своих страхов, не знает?

\section{Сущность культуры старости}

Как культура жизни старость складывается при условии, что общество признает своеобразие жизни пожильх людей и создает спеииальные условия для такой жизни (пенсии, социальное и медицинское обслуживание, определенные законы, льготы, забота со стороны семьи и пр.). Другое условие - усилия и рабоmа самих пожильх людей и стариков: 
выстраивание своего рода комщепщи старости и ее реализация. Третье осмысление старости в культуре (литература, музыка, наука и пр.) создание, так сказать, «семиотики старости». Обеспечивая условия для старости, обшество может и перегнуть палку. Английский врач и писатель А. Комфорт писал, что мы можем сделать людей социально старыми, если раньше времени отправим их на пенсию. Можем таким способом сделать их старыми даже физически, поскольку у человека психические, физические и общественные факторы обусловливают друг друга.

Если сравнить культуру старости с детской, то можно указать на существенные различия. Ребенок только идет $\mathrm{k}$ самостоятельной жизни и поведению, а пожилой человек исходно самостоятелен. Ребенок осознает себя вместе с родителями (феномен прамы), а пожилой человек даже в семье, которая может о нем заботиться, ощущает себя самостоятельной личностью, не сливающейся с родными. Ребенок стремится к миру взрослых, а пожилой человек является взрослым; другое дело, что ему приходится заново устанавливаться по отношению к миру и другим людям. Стихия ребенка игра и фантазия, а пожилой человек давно ушел от этих форм жизни. Ребенок не озабочен поиском смысла жизни, а пожилой человек нередко вынужден решать эту проблему. В чем же тогда специфика и сущность старости? «По мнению К. Юнга, потребность выработать целостный взгляд на свою жизнь, обрашенность внутрь себя, самосозерцание являются долгом и необходимостью в старости. Результатом этой психологической перестройки является появление новой жизненной позиции, рационального взгляда на свое существование и вместе с тем созерцательного, устойчивого психического и нравственного равновесия. К. Юнг считал, что закат человеческой жизни должен иметь собственное значение, а не быть жалким придатком к заре жизни. В связи с этим К. Юнг считал непоправимой ошибкой “проводить сумерки жизни в соответствии с программой ее зари”, нести "в сумерки закон утра". Успешность, адаптивность старения определяется тем, насколько человек оказывается подготовленным к вступлению в новую фазу жизни, к тем задачам, которые несет с собой поздний возраст. Поэтому, рассуждая об учащении нервных срывов при старении, К. Юнг видел их причину в том, что во вторую половину жизни люди вступают неподготовленными» (Ермолаева, 2002, с . 4).

В каком смысле люди оказываются неподготовленными? А в том отношении, что они начинают жить в новых условиях (перестают работать, не знают, чем себя занять, все больше болеют, не понимают, как осмыслить конечность своей жизни и смерть, и т.д. и т.п.), но представления о жизни и самом себе у людей старые. Чтобы жить по-новому, пожилой человек должен перестроиться, увидеть мир и себя иначе, чем прежде, нашупать новый образ жизни, который бы позволял справляться с болезнями, преодолевать страх перед смертью, заполнить свою жизнь интересными занятиями и делами. Сделать это невозможно, не выстроив концепцию старости, т.е. 
новое представление о реальности (ведь старая реальность как бы отделяется от человека и уходит в будущее), новое ощущение себя (ну вот я пожилой, старый человек и во многом один, поскольку старею и буду умирать, в то время как другие будут жить), не определив новый сценарий и стратегию жизни (например, надо «сбавить обороты», больше заниматься здоровьем, подумать о душе, найти посильное и интересное занятие и пр.).

«По сути, - пишет Ермолаева, человек на пороге старости решает для себя вопрос: пытаться ли ему сохранять и формировать новые сферы своих социальных связей или перейти к жизни, ограниченной кругом своих житейских интересов и интересов близких, то есть перейти к жизни в целом индивидуальной. Это решение определяет две основные стратегии адаптации - сохранение себя как личности и сохранение себя как индивида» (Ермолаева, 2002, с. 2). Близких взглядов придерживается и А.Г. Лидерс, утверждающий, что ведущей деятельностью пожилого человека является особая «внутренняя работа», направленная на принятие им своего жизненного пути.

Концепциям старости несть числа, начиная от оптимистических, кончая пессимистическими и нулевыми (т.е. отсутствием таких концепций вообще). «Быть старым,пишет Герман Гессе,- такая же прекрасная и необходимая задача, как быть молодым, учиться умирать и умирать - такая же почтенная функция, как и любая другая, - при условии, что она выполняется с благоговением перед смыслом и священностью всяческой жизни. Старик, которому старость, седины и близость смерти только ненавистны и страшны, такой же недостойный представитель своей ступени жизни, как молодой и сильный, который ненавидит свое занятие и каждодневный труд и старается от них увильнуть. Короче говоря: чтобы в старости исполнить свое назначение и справиться со своей задачей, надо быть согласным со старостью и со всем, что она приносит с собой, надо сказать ей “да". Без этого “да”, без готовности отдаться тому, чего требует от нас природа, мы теряем стары мы или молоды - ценность и смысл своих дней и обманываем жизнь» (Гессе, 1987, с. 322).

Но, пожалуй, значительно больше вариантов неправильных установок в отношении собственной старости, включая полное ее отрицание. Здесь и регрессия, проявляющаяся в форме «детского» требования помощи независимо от состояния здоровья, и добровольная изоляция, и безрезультат ные попытки сохранить уходяшую зрелость. У многих пожилых людей возникает ощущение неудовлетворенности жизнью, оскудение чувств, «что вместе с хроническим недомоганием и прогрессирующей утратой интереса к окружающему провоцирует негативные изменения личности в форме "заострения" личностных черт» (Ермолаева, 2002, с. 4).

Итак, сущность культуры старости - это выстраивание концепции старости и ее реализация. В свою очередь, последняя предполагает, с одной стороны, как я говорил, изменение реальности и нахождение смысла своей жизни, с другой - возобновление жизни в новых условиях. Мераб Мамардашвили неоднократно 
обращал внимание на то, что жизнь современного человека не осуществляется автоматически, она требует усилий и творчества. Тем более в старости. Нужно находить в себе силы для жизни, поддерживать свое здоровье в условиях нарастания болезней, собирать себя вновь и вновь, находить смысл жизни и пр. Вопрос здесь в том, можно ли найти смысл жизни в старости, если жизнь кончается. Конечно, для верующего человека она не кончается, но ведь не все могут поверить в Бога, и даже очень многие в этой жизни не сталкивались с религиозным опытом. Говоря «находить смысл и изменение реальности», я выражаюсь не совсем точно. И то и другое нужно создать, причем не произвольно, а органично для себя (хотя действительно, мы осознаем эту работу в естественной модальности).

На что здесь, спрашивается, можно ориентироваться? Может быть, на правильную жизнь? Возьмем для примера поддержание в старости здоровья. Часто для многих это самоцель. В то же время здоровье человека тесно связано с другими формами его бытия и с правильной жизнью в целом. Поясню. С точки зрения современных антропологических исследований человек напоминает кентавра и матрешку одновременно. Самая значимая и руководящая матрешка - личность человека. Личность предполагает самостоятельное поведение и самостроительство в отношении своей жизни. Другие матрешки - психика, телесность, биологический организм. Это если мы идем от полюса социального поведения (одна ипостась кентавра). Если же сменить полюс, то последо- вательность обратная: биологический организм, телесность, психика, личность.

Относительно такого понимания человека и современной социокультурной ситуации ни одно из традиционных определений здоровья не работает. Считается, что здоровый это не больной. Но сегодня большинство болезней можно минимизировать за счет правильного образа жизни и медицинских услуг. Кроме того, с точки зрения биологических норм (давление, кровь, отсутствие хронических заболеваний и пр.) человек может считаться здоровым, но его психика, телесность и личность находятся не в лучшем состоянии. Здоровый - это состояние физического, психического и социального благополучия. А такого, как правило, вообще не бывает. Мы постоянно болеем, а полное благополучие нам только снится.

Для здоровья человека более существенно, может ли он себя реализовать, живет ли в ладу сам с собой, ясна ли ему жизненная перспектива (план личности), справляется ли он со своими стрессами и настроением, может ли поддерживать нужные отношения с другими людьми, общаться с ними, умеет ли мобилизовать себя, обладает ли необходимыми способностями и т.п. (план психики), обладает ли его тело нужными качествами для жизни (план телесности), получает ли его организм необходимое для жизни питание, движение, среду. Не менее сушественно, умеет ли человек менять свое поведение, переходя на следующие этапы взросления или старения. Например, правильно расширять свои претензии и потребности или, 
наоборот, свертывать их по мере приближения старости. Нетрудно заметить, что все указанные особенности жизни человека не складываются сами собой, они предполагают специальную работу, образ жизни и социальные условия.

Здоровье отдельного человека сегодня лучше понимать не как отсутствие болезней или иллюзорное благополучие, а прежде всего как работу человека и качество, характер жизни, складывающиеся под влиянием этой работы. Главные ее составляющие такие. Построение личной концепции здоровья (а на последнем этапе жизни - концепции старости). Включение в нее сочиальных требований к здоровью, при том что одновременно нужно развивать критическое отношение к услугам, которые предлагает государство или медицинский бизнес, корректировать их на основе своей личной концепции здоровья. Минимизация болезней с использованием как личных возможностей (здоровый образ жизни, работа с собственными ценностями и пр.), так и всех средств, предоставляемых обществом. Формирование установок на возобновление жизни и здоровья, что предполагает смену форм поведения и отношения к своему здоровью по мере старения. Умене работать и справлатьса со своими проблемами и стрессами. Подчинение всей указанной работы общему сценарию правильной жизни.

Хотя сторонники духовно-экологического подхода утверждают, что правильная жизнь - залог здоровья, они не ставят во главу угла исцеление или поддержание здоровья человека. Их цель другая - именно правильная жизнь, понимаемая, конеч- но, каждым по-своему (в одном случае это религиозное или эзотерическое спасение, в другом - нравственная жизнь и служение людям, в третьем - достойное поведение и общественно значимые деяния и т.п.). Но, может быть, все же есть вероятность понять, какая именно правильная жизнь способствует здоровью и что в такой жизни здоровью способствует? К сожалению, ответить на эти вопросы трудно или даже невозможно. Для одних правильная жизнь заключается в творчестве, для других - в помощи людям или брошенным животным, для третьих в вере, для четвертых, пятых, шестых... - короче, нет единственного правильного пути жизни, их много разных.

Как материал для размышления по поводу этой темы приведу два конкретных примера понимания правильной жизни. Экзистенциальное самоопределение Мишеля Фуко (понимание им правильной жизни) включает следующие положения: конституировать, делать себя, ориентируясь на реальность, осмысляя ее; сопротивляться тем социальным институтам, которые подавляют личность; делать свою жизнь как произведение искусств; жить и мыслить так, чтобы преодолевать свое прежнее сложившееся бытие; быть открытым новому, переосмыслять и себя, и внешнюю реальность. «Я мечтаю об интеллектуале, - писал Фуко, который сокрушает очевидности и общие места, который в инерции и ограничениях настоящего находит и отмечает слабые места, трещины, силовые линии, который постоянно находится в движении, не знает точно, куда он двинется и как он 
будет думать завтра, потому что он уделяет слишком большое внимание настоящему». Фуко интересовала возможность «узнать, в какой степени работа осмысления своей собственной истории может освободить мысль от того, что она мыслит втайне от самой себя, и дать ей возможность мыслить иначе». «Из идеи того, что Я не дано нам, есть только одно практическое следствие: мы должны творить себя как произведения искусства». Быть свободным «означает не быть рабом самого себя и своих стремлений - это подразумевает, что мы устанавливаем с самими собой известные отношения господства, укрощения, которые называются arche - власть, сдерживание». Эта критическая функция философии до известной степени проистекает из сократовского императива: «Занимайся собой», т.е. «самообладанием положи в основу себя свободу» (цит. по: Дикон, 2008, с. 53-60).

У автора данной статьи несколько иная картина. Он стремится жить в ладу с самим собой. Старается делать себя, но не как произведение искусств. С одной стороны, он пытается соответствовать своему пониманию, что́ есть человек, с другой критически осмысливать эти свои убеждения. С одной стороны, следует принципу, что «человек сам себе не судья», с другой - считает, что критическое отношение к себе залог правильной жизни. С одной стороны, автор принимает себя, каким он является «здесь и сейчас», с другой - работает над собой, надеясь со временем измениться в лучшую сторону. Он не считает себя гением, но делает все, чтобы через него состоялись культура и жизнь. Автор признает свою зависимость от других людей и совместность с ними своей жизни. Поэтому он старается помочь людям и сделать все, чтобы способствовать культуре. Одновременно готов отстаивать свою свободу как личность и возможность критического отношения к существующей жизни. Духовность и мышление для автора являются ценностями, нравственное и порядочное поведение не пустой звук. Наконец, он не исключает, что может заблуждаться по поводу правильности своего пути.

Можно заметить, что наши с Фуко представления исходят из убеждения, что нельзя раз и навсегда конституировать жизненный путь личности, что в течение жизни это приходится делать неоднократно. Тем не менее это не означает, что нет определенных экзистенциальных универсалий, что жизнь человека можно конституировать произвольно. Мы конституируем себя в пространстве культурных оппозиций и общих условий, которые, конечно же, меняются со временем, но не исчезают. В число этих общих условий и универсалий входят традиции, которым мы следуем и которые одновременно преодолеваем, и сама работа по конституированию жизни личности. В наше время перемен и перехода, во внеэтическую эпоху об этом не стоит забывать, поскольку от характера конституирования себя во многом будет зависеть и качество нашей жизни. Важную роль в конституировании себя и реальности играют поступки человека (пересмотр своей жизни, решение ее изменить, экзистенциальный выбор и т.п.).

Если же говорить об идеале здоровья автора, то он таков. Меньше 
болеть обычными заболеваниями, если заболел, то скорее выздоравливать, справляться с хроническими заболеваниями, признавать свое старение, быть готовым к различным стрессам и экстремальным ситуациям, жить в ладу с собой, полноценно реализовать себя. Для осуществления этой «программы здоровья» он гуляет в парке, делает зарядку, старается жить правильно, работает с собой, обрашцается в случае обычных и хронических заболеваний к врачам и пр. Однако стоит отметить, что не программа оздоровления была исходной, а установка на правильную жизнь и попытка воплотить ее в жизнь. Реализуя установку на правильную жизнь, я вскоре заметил, что и здоровье постепенно стало улучшаться. Проанализировав, что он делает и куда двигается, автор и сформулировал свою программу здоровья.

Оказавшись в преклонном возpacte, я стал продумывать свою жизнь. Например, понял, что нужно все больше времени тратить на свое здоровье, что важно постепенно отказываться от желаний и форм жизни, которые ты осуществляешь через силу или для которых уже нет условий (а такой отказ, как известно, дается с большим трудом), что в старости человека держат творчество и востребованность, что для возобновления полноценной жизни нужно примиряться со своими возможностями, которые уменьшаются, что все больше помогают жить музыка и природа, что именно продумывание сущности смерти (и жизни) практически полностью снимает перед ней страх. Примерно о том же пишут Роман Бацман и Мария Ермолаева.
«Условием длящейся или нарастающей зрелости является творчество во всех его проявлениях, включая творчество собственной жизни, каждого его дня. Замена старения нарастающей зрелостью - нравственный долг перед собой. Переживание продления собственной жизни в детях, незавершенных делах, переживание социального бессмертия - это условия преодоления старения как увядания и деградации. Порыв к жизни и творческие силы побеждают старость как психологический возраст и "снимают" его с траектории жизненного пути» (Ермолаева, 2002, с. 14).

«Чтобы жить без страха, следует позволить Богу решить за нас, прежде всего, вопрос конца нашего земного сушествования и с благодарностью принять Его “волю”. Христианин верит в то, что его жизнь заканчивается в оптимальный для этого момент: самый благоприятный для спасения его души. Человеку не следует спать в духовном смысле этого слова. Он должен быть открыт всему, что ждет его на пути. Психолог В. Франкл пишет о том, что без страдания и смерти жизнь не полна. Во всем необходимо обнаружить смысл. Как жить, так и умирать человек должен осмысленно. В беседах митрополита Антония Сурожского есть пронзительные слова: "Не важно - жив ты или мертв, важно, ради чего ты живешь или во имя чего ты умираешь". Но в чем же мы можем обнаружить смысл смерти? Во-первых, она смиряет человека. Смирение есть единственная тональность речи для диалога с Богом. Творение осознает себя и свою потребность во встрече с Творцом. Вовторых, сознание смерти облагора- 
живает жизнь, не позволяет человеку потерять себя в суете. В-третьих, смерть объединяет всех. Столкнувшись со смертью, человек осознает свою причастность человечеству» (цит. по: Там же, 2002, с. 7).

Может показаться, что в сущность старости должны входить умирание и смерть. Думаю, что нет. Они входят в концепцию старости: и то и другое нужно признавать и продумывать. Но сама старость - это именно жизнь, несовместимая со смертью. Продумать же жизнь как ограниченную смертью необходимо. При этом приходишь к интересному парадоксу: жизнь человека как биологического существа конечна, а как личности и социального индивида бесконечна. Мы недостаточно понимаем, что наша душевная и духовная жизнь задается культурой и социумом и принадлежит не только нам, но и этим деиндивидуальным формам коллективной социальной жизни. Социум, подобно Солярису в романе С. Лема, вечен (пока существуют Земля и на ней люди), но он живет посредством вас и меня. И мы с вами живем посредством Социума (кстати, осознается он по-разному: рационально как культура, или социальность, или человечество, религиозно - как Бог). Но нам кажется, что человек - это одно, как говорили в античной и средневековой культуре, «микрокосм», а социум - другое, «макрокосм». Как принадлежащие социуму и культуре мы бессмертны, а как биологические сушества смертны. Но здесь нет трагедии, если только жить правильно, поскольку, как уже говорилось, в сущность старости смерть и умирание не входят. В концепцию старости смерть входит, но за ней стоит видеть продолжение жизни, пусть не нашей, но и нашей, вечной. Об этом замечательно размышлял Ф. Тютчев:

Если смерть есть ночь, если жизнь есть день -

Ax, умаял он, пестрый день, меня!.

И сгущается надо мною тень,

Ко сну клонится голова моя...

Обессиленный, отдаюсь ему...

Но все грезится сквозь немую тьму Где-то там, над ней ясный день блестит И незримый хор о любви гремит...

Относительно недавно я рискнул представить, тоже в поэтической форме, переход к этой вечной жизни:

Мне сон приснился странный,

Что умерли мы оба,

И словно птицы легкие

Поднялись в небеса.

В сияющих чертогах

Предстали перед Господом,

Там ангелов хранителей

Звучали голоса.

«Покайтесь, мои путники» -

Сказал Творец спокойно.

И книгу судеб толстую

Из шкафчика достал.

«Грехов различной тяжести

За жизнь скопилось много», Страницу за страницей Он

Задумчиво листал.

И пели хоры ангелов,

Так страшно и прекрасно.

Внимая нам и Господу,

Склоняя к долу взгляд.

Что мы как на концерте

Заслушались невольно,

Забыв, зачем поспешно

Явились в этот град. 
Очнулись мы от голоса

Ангела хранителя.

«Позволь замолвить слово», -

Он Господа просил.

Творец кивнул приветливо,

Захлопнул книгу скорбную,

И голову прекрасную

На облака склонил.

«Прости, Отец Небесный,

Грехи не отрицаем.

О них мы сами ведаем,

Страдаем и корим

Себя за равнодушие,

За тех, кого забыли,

Кому не помогали,

Хотя и были с ним.

Но, может быть, достойны

Мы все же нисхожденья,

Поскольку честно жили

В терпенье и трудах.

Детей поднять сумели,

Хотя они, конечно,

Ну, не совсем, конечно,

Как бы хотелось - Aх!

Нас ангел взял за руки,

На облако поставил.

Оно как шар воздушный

По небу поплыло.

«Теперь вы сами ангелы», -

Сказал хранитель грустно.

И, перья растопырив,

Легли мы на крыло.

Я привел свои стихи не только для иллюстрации, но и для того, чтобы обратить внимание на, как сегодня модно говорить, нашу интерсубъективность. Я вместе с любимой женой, мы с Богом, олицетворяющим для нас других людей и в целом человечество. Принадлежность к социуму и культуре - это, в частности, моя связь с другими людьми. Хотя обе формы коллективной деиндивидуальной жизни не сводятся собственно к людям - есть много другого: язык, социальные институты, материальная среда, техника и пр., - все же без людей социум и культуру помыслить невозможно. Без связи с людьми я не могу существовать, в критических ситуациях я черпаю энергию и помощь от других, в свою очередь, я стараюсь посильно помогать людям, мне не безразлично, как они живут и каким образом будут жить, даже когда меня не будет. Фраза «он любил людей» вовсе не просто красивая формула: это символ веры в людей, в нашу интерсубъективность. Посредством интерсубъективности и любви к людям мы обретаем бессмертие, но только если живем «не как живется», а стараемся жить правильно, работая на других, социум и культуру.

Здесь можно определить и смысл жизни в старости. Надо жить так, чтобы сознательно, с нашим собственным пониманием пользы и блага войти в социум. Что значит войти, если как биологические существа мы умрем? Но как люди, принадлежащие культуре и социуму, мы бессмертны, и наша жизнь является достоянием других людей как в настоящем, так и в будущем. Стать достоянием для социума и культуры, для живущих сейчас и тех, кто будет жить в дальнейшем, означает то, что мы будем участвовать в жизни других людей, даже когда нас не будет. Участвовать примером нашей жизни, детьми и внуками, нашими трудами. Эзотерик Рудольф Штейнер хорошо понимал это. Более того, он вывел подобное достояние на уровень 
самой идеи послесмертного существования. В его учении эзотерик в том мире подлинной реальности участвует в творчестве живущих, помогает Земле в ее развитии, короче, выступает, хотя его нет в живых в обычном понимании, существенным моментом жизни и творчества живущих (Розин, 1998, с. 135-137).

В свою очередь, чтобы достичь этого, нашу жизнь надо завершить, правильно артикулировать и представить. Именно такую задачу и решает человек в старости. Завершение жизни, мыслимая в будущем смерть, любовь к людям и создают ту самую точку «вненаходимости», о которой пишет Бахтин, которая позволяет завершить нашу жизнь и представить ее для других. Поэтому не безразлично, как мы живем в старости и что делаем. Когда Фуко пишет, что он хочет сделать из своей жизни произведение искусства, то имеет в виду свою жизнь как пример для других, точнее, хочет войти в культуру вполне определенным образом. Но, пожалуй, впервые на этот путь указал Платон.

В «Государстве» Платон описывает перипетии душ в загробном мире. Вроде бы судьба человека полностью определяется богами загробного мира, однако выбор дальнейшей судьбы («жребия») трактуется Платоном как вполне закономерный, обусловленный тем, как человек жил, каков его разум; зависит этот выбор и от личности умершего. «После этих слов прорицателя сразу же подошел тот, кому достался первый жребий, он взял себе жизнь могущественного тирана. Из-за своего неразумия и ненасытности он произвел выбор, не поразмыслив, а там таилась роковая для него участь пожирание собственных детей и другие всевозможные беды. Когда же он потом, не торопясь, поразмыслил, он начал бить себя в грудь, горевать, что, делая свой выбор, не посчитался с предупреждением прорицателя, винил в этих бедах не себя, а судьбу, богов - все что угодно, кроме себя самого... Случайно самой последней из всех выпал жребий идти душе Одиссея. Она помнила прежние тяготы и, отбросив всякое честолюбие, долго бродила, разыскивая жизнь обыкновенного человека, далекого от дел; наконец, она насилу нашла ее, где-то валявшуюся, все ведь ею пренебрегли, но душа Одиссея, чуть ее увидела, с радостью взяла себе» (Платон, 1994а, с. 417, 418-419).

Здесь возникает естественный вопрос: почему все это не мифология и, может быть, платоновское учение о загробном мире и воздаянии души за ее земную жизнь и поступки - это всего лишь религиозная вставка в духе египетской Книги мертвых? Нет, не думаю. Да, действительно, Платон использует, как и в других своих диалогах, представления о богах и демонах. Но каким образом? Боги у Платона, в отличие от богов распространенных мифов, обеспечивают решение задач, которые его интересуют.

Среди этих задач, например, убедить становящуюся античную личность действовать разумно, а не просто удовлетворять свои желания и страсти. Действовать так, чтобы потом не жалеть о содеянном. Сюда же относится задача объяснить личности, что ее жизнь не ограничивается только существующими ситуациями и событиями, что есть реальность - 
послесмерное бытие, включающая жизнь человека как свой момент, причем от того, как человек живет на земле, зависит характер этого бытия. Стремится Платон объяснить античной личности, что смерть есть благо, если человек живет правильно и разумно, но зло и страдание, если он живет неправильно и неразумно. Важной личной проблемой для Платона является определение способа жизни, который позволяет встречать смерть спокойно, без страха. «Такой человек, - пишет Платон в «Послезаконии», - даже восполнив смертью удел своей жизни, на смертном одре не будет, как теперь, иметь множества ощущений, но достигнет единого удела, из множественности станет единством, будет счастлив, чрезвычайно мудр и вместе блажен» (Платон, 1994б, с. 458).

По сути, само понимание загробного бытия у Платона работает на его концепцию личности, не забудем, что главное, что должна сделать душа в царстве Аида, - осуществить правильный выбор своей судьбы. Но правильный выбор по Платону - это не одномоментный акт, а размышление, обдумывание своей прошедшей жизни, в конечном счете, как показывает анализ «Федона», «Пира», «Го- сударства» и ряда других диалогов, правильный выбор предполагает сложную духовную работу («вынашивание духовных плодов», освобождение от уз тела и неразумных желаний, жизнь истиной, идеями и пр.).

К кому обращается Платон, рассказывая об идеальном государстве или о том, как он завершает свою жизнь? К другим людям. А в отношении самого себя что он хочет сказать? Не сказать, а настроиться на правильную жизнь, которая и сделает Платона бессмертным. Понятно, что таково решение Платона, я решаю иначе, другие тоже по-своему. Но думаю, общее здесь в том, что правильная жизнь в старости направлена на осмысление прожитой и текущей жизни, на помощь другим, на вхождение в социум и культуру (формы же такого вхождения и участия в культуре могут быть очень разные).

Завершая свою жизнь, будем помнить, что качество нашей старости во многом зависит от нас самих. Мы может умереть еще при жизни, но можем сделать свою старость если не счастливой, то во всяком случае полноценной, достойной и правильной. Выбор, как говорил, Платон, за человеком, боги не виноваты.

\section{Литература}

Бацман, Р. (2003). Духовные проблемы пожилых людей. В кн. Р. С. Яцемирская, Л. Н. Хохлова, Э. В. Карюхин, А. В. Флинт (ред.), Проблемы старости: духовные, медицинские и социальные аспекты: Сб. трудов. М.: Свято-Димитриевское училище сестер милосердия.

Гессе, Г. (1987). О старости. В кн. Г. Гессе, Письма по кругу (с. 322-324). М.: Прогресс.

Дикон, Р. А. (2008). Производство субъективности. Логос, 2(65). 21-64.

Ермолаева, М. (2002). Практическая психология старости. М.: ЭКСМО-Пресс.

Леон-Портилья, М. (1961). Философия нагуа. М.: Иностранная литература. 
Платон. (1994а). Государство. В кн. Платон, Собрание сочинений (т. 3, с. 79-421). М.: Философское наследие.

Платон. (1994б). Послезаконие. В кн. Платон, Собрание сочинений (т. 4, с. 438-460). М.: Философское наследие.

Розин, В. М. (1998). Путешествие в страну эзотерической реальности. Избраниые эзотерииеские уиения. М.: УРСС.

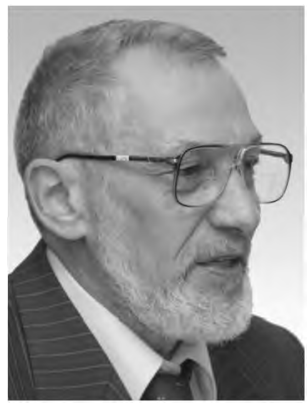

Розин Вадим Маркович - главный научный сотрудник, Институт философии РАН, доктор философских наук, профессор.

Сфера научных интересов: семиотика, культурология, гуманитарный подход.

Контакты: rozinvm@gmail.com

\title{
Old Age as a Psychological and Cultural Phenomenon
}

\author{
V.M. Rozin ${ }^{\mathrm{a}}$ \\ ${ }^{a}$ Institute of Philosophy of Russian Academy of Sciences, 12 build. 1 Gonchamaya Str., Moscore, 109240, \\ Russian Federation
}

\begin{abstract}
The article views the old age in the author's framework of "cultures of human life". The author suggests distinguishing "culture of childhood", "culture of adolescence and youth", and several "cultures of an adult". Each culture of human life is characterized by the specifics of functioning and worldview (consciousness), as well as by the specifics of socialization. A brief description of each culture of life is presented. Then the problems of old age are analyzed (parting with the habitual way of life, illnesses, loss of meaning of life, etc.), as well as traditional ways for old people to combat these problems. The author hypothesizes that the essence of the culture of old age is building the concept of old age and then its realization. In its turn, realization suggests, on the one side, changing of reality and finding meaning of life, and on the other side, renewal of life in new circumstances. By the example of understanding human's health and place that it should take in the old age, the conditions of realization of this hypothesis are discussed. Health of a human, as the author believes, is better to understand not as an absence of illnesses or an illusory well-being, but, in the first place, as human's work and quality, specifics of life that develops under the influence of such work. Its main components are following: (1) building of a personal conception of health (and in the last stage of life - a conception of old age); (2) inclusion of social
\end{abstract}


demands in it (simultaneously one needs to develop critical attitude toward services that the state or medical business offer, and make corrections on the basis of one's personal conception of health); (3) minimization of illnesses with the usage of both personal capacities (healthy lifestyle, work with personal values, etc.), and all other means that society provides; (4) formation of a position to renew life and health, which suggests change of behavior and attitudes to one's health with the age; (5) ability to work and deal with own problems and stressors; (6) submission of all the described work to the general scenario of the proper life. The article finishes with the discussion of 3 conditions to reproduce old age as culture. Firstly, this culture is supported by society, giving it special conditions and institutions. Secondly, the biological nature itself works to reproduce old age - people age, become sick, advance to their end. Thirdly, the combined work of human and culture - human creates individual conceptions of the old age and realizes them, and culture develops various semiotics of the old age, which people use.

Keywords: old age, age, conception, meaning of life, crisis, cultures of life, illnesses, fear, health, death.

\section{References}

Batsman, R. (2003). Dukhovnye problemy pozhilykh lyudei [Spiritual problems of the old people]. In R. S. Yatsemirskaya, L. N. Khokhlova, E. V. Karyukhin, \& A. V. Flint (Eds.), Problemy starosti: dukhornye, meditsinskie i sotsialnye aspekty: Sbomik trudoo [Problems of the old age: spiritual, medical and social aspects. Collected works]. Moscow: Svyato-Dimitrievskoe uchilishche sester miloserdiya.

Dikon, R. A. (2008). Proizvodstvo starosti [Production of old age]. Logos, 2(65), 21-64.

Ermolaeva, M. (2002). Prakticheskaya psikhologiya starosti [Practical psychology of old age ]. Moscow: EKSMO-Press.

Hesse, H. (1987). O starosti [On old age]. In H. Hesse, Pis'ma po knugu [Letters full-circle] (pp. 322-324). Moscow: Progress.

León-Portilla, M. (1961). Filosofiya nagua [Philosophy of nahuatl]. Moscow: Inostrannaya literatura. (Transl. of: León-Portilla, M. (1956). La filosofía nahuatl: estudiada en sus fuentes [Philosophy of nahuatl: study of sources]. Mexico City: Instituto Indigenista Interamericano. (in Spanish))

Plato. (1994a). Gosudarstvo [State]. In Plato, Sobranie sochinenii [Collected works] (Vol. 3, pp. 79-421). Moscow: Filosofskoe nasledie.

Plato. (1994b). Poslezakonie [After the laws]. In Plato, Sobranie sochinenii [Collected works] (Vol. 4, pp. 438-460). Moscow: Filosofskoe nasledie.

Rozin, V. M. (1998). Puteshestvie v stranu ezotericheskoi real'nosti. Izbrannye ezotericheskie ucheniya [A journey to the country of esoteric reality. Chosen esoteric learnings]. Moscow: URSS.

Vadim M. Rozin - chief research fellow, Institute of Philosophy of Russian Academy of Sciences, D.Sc., professor.

Research area: semiotics, culturology, humanistic approach.

E-mail: rozinvm@gmail.com 